\title{
LOS EXEMPLA DEL CÓDICE 48 DE LA BIBLIOTECA DE LA CATEDRAL DE PAMPLONA
}

\author{
Beatriz Marcotegui Barber \\ Doctora en Historia \\ beatriz.marcotegui.barber@navarra.es
}

\section{La nueva predicación del siglo XIII y sus fuentes}

Un sermón es, en esencia, un discurso oral pronunciado por un predicador que, sobre la base de un texto bíblico, se dirige a una audiencia de fieles con una intención formativa y persuasiva, no sólo para divulgar las verdades de fe, sino también para inculcar la doctrina moral de la Iglesia ${ }^{1}$. De hecho, desde los primeros años del Cristianismo, la predicación constituyó uno de los medios prioritarios de transmisión de la fe. Sin embargo, con el tiempo esta práctica se fue restringiendo al ámbito religioso o monástico (ad cleros), descuidando de esta manera la atención pastoral a la comunidad de fieles. En este sentido, la celebración en 1215 del IV Concilio de Letrán constituyó un hito decisivo, pues entre otras medidas impulsó la rectificación moral del clero y recordó su deber pastoral de predicar y administrar los sacramentos al pueblo de Dios (ad populum). Asimismo, el canon décimo de praedicatoribus instituendis obligaba a los obispos a que encomendaran esta misión a personas con adecuada formación y costumbres rectas.

De este modo, desde fines del siglo XII y principios del XIII se puede hablar de una nueva predicación, que comenzó a gestarse en el entorno de las escuelas de Teología de París: más práctica, más cercana y basada en el aprendizaje de la Teología. Igualmente, desde el siglo XII los cistercienses hicieron un importante esfuerzo por predicar a gentes iletradas y enseñarles el sentido de las prácticas religiosas, empleando como instrumento principal la narración. Este sistema lo adoptaron unos años más tarde las comunidades mendicantes

\footnotetext{
${ }^{1}$ Esta definición está inspirada en la que propone Beverly M. Kienzle en «Introduction», en The sermon, dir. de Beverly M. Kienzle, Turnhout, Brepols, 2000, p. 151.
} 
e hicieron de la predicación una profesión socialmente reconocida e incluso remunerada, y cuyo ejercicio estaba reglamentado, pues requería una preparación y técnicas específicas ${ }^{2}$. Su discurso se sistematizó siguiendo un esquema regular y típicamente escolástico, nacido en el seno de las universidades y que se codificó en tratados o Artes praedicandi ${ }^{3}$. Por ello, el siglo XIII se caracterizó por la proliferación de instrumentos para la predicación, tales como colecciones de modelos de sermones, relatos ejemplares o repertorios de distinctiones bíblicas, que eran difundidos por toda Europa especialmente desde París. Estas obras estaban normalmente escritas en latín porque sus lectores eran, en general, clérigos conocedores de esta lengua ${ }^{4}$.

Las variantes textuales de estos instrumentos son muy diversas: desde materiales útiles para la preparación del sermón, pasando por apuntes de oyentes tomados durante su pronunciación, hasta textos más elaborados, fruto de una redacción posterior del autor con vistas a servir de modelo a otros posibles predicadores 5 . Como sistematiza Pedro M. Cátedra, los predicadores más iniciados y capaces de organizar sus propios sermones emplearían también otros libros, como sumas de filosofía y teología o repertorios de símiles y exempla. Y los predicadores más consagrados compondrían sus propios sermones tomando como fuente la Biblia, con sus glosas y concordancias, y alguna colección de distinctiones ${ }^{6}$.

Por lo tanto, en las bibliotecas europeas se conserva una gran cantidad de textos relacionados con la predicación, y también en la de la Catedral de Pamplona que, entre otros muchos libros, atesora una valiosa colección de diez códices de diversa procedencia, fecha y autor ${ }^{7}$. Dos de ellos contienen

${ }^{2}$ Hervé Martin, Le métier de prédicateur à la fin du Moyen Âge 1350-1520, París, Cerf, 1988, p. 188.

${ }^{3}$ Sin embargo, se han documentado varios casos de predicadores (Maurice de Sully, v. gr.) que, cuando se dirigían a audiencias compuestas por laicos, abandonaban la estructuración escolástica del sermo modernus y empleaban el método patrístico de predicar-la homilía-. Vid. Nicole Bériou, L'avenement des maitres de la parole. La prédication effective à Paris au XIII siècle, París, Études augustiniennes, 1998, I, p. 480; Manuel A. Sánchez Sánchez, «De homiliarios medievales: el ms. 49 del Archivo de la Catedral de Pamplona», en La primitiva predicación española medieval: tres estudios, Salamanca, SEMYR, 2000, p. 102.

${ }^{4}$ Nicole Bériou, «Les sermons latins après 1200», en The sermon, ob. cit., pp. 363-364.

${ }^{5}$ Vid. Nicole Bériou, «Les sermons», en Identifier sources et citations, dir. Jacques Berlioz, Brepols, 1994, pp. 201-209.

${ }^{6}$ Pedro M. Cátedra, «El taller del predicador: a propósito de un sermón castellano para el Domingo de Ramos (RAE, Ms. 294)», en Pensamiento medieval hispano: homenaje a Horacio Santiago-Otero, coord. de José M. Soto Rábanos, Madrid, CSIC, 1998, pp. 308-311.

${ }^{7}$ José Goñi Gaztambide publicó, en varios artículos, un catálogo de la mayor parte de los códices de la Biblioteca de la Catedral de Pamplona: los de contenido religioso en «Catálogo de los manuscritos teológicos de la Catedral de Pamplona», en Revista española de Teología, 17 (1957), pp. 231-258, 383-418 y 557-594; 18 (1958), pp. 61-85. Para un estudio y edición parcial de los códices relacionados con la predicación conservados en esta biblioteca vid. Beatriz Marcotegui, Instructio morum et fidei. La predicación en el reino de Navarra en el siglo XV, Pamplona, Gobierno de Navarra, 2009. 
textos escritos en romance navarro, lo cual hace bastante probable su utilización dentro del ámbito del reino de Navarra. En este artículo se analiza uno de ellos, el número 48, que recoge varios materiales útiles para la preparación de sermones, entre ellos una colección de siete exempla escritos en este dialecto ${ }^{8}$.

Al estudiar este tipo de textos no hay que olvidar que fueron escritos, compuestos o compilados no tanto con una finalidad estética, sino más bien didáctica, para transmitir de manera asequible las verdades de fe y los comportamientos morales correctos a un público laico con poca formación religiosa. No obstante, también se buscaba entretener, impresionar, impactar al oyente, empleando los recursos retóricos, estéticos y literarios del momento. Y es que para un análisis completo de ellos se requiere un enfoque interdisciplinar. En primer lugar, desde la Teología, por su contenido doctrinal y pastoral; en segundo lugar, desde la Filología, por el modo en que se encuentran escritos, en lengua romance o en latín; también, desde la Historia de la Literatura, pues se trata de relatos literarios, compuestos o empleados para hacer más comprensible el mensaje que pretendían comunicar; y por último, desde la Historia, ya que son textos que reflejan los modos de vida y la mentalidad de una época histórica determinada, especialmente su dimensión espiritual.

En este artículo se analizan los exempla desde una perspectiva literaria, buscando identificar su filiación y relación con otras versiones de los relatos, en concreto con aquellas que están más cercanas a la colección navarra, ya que se trata de textos muy difundidos y presentes, con variantes, en muchos otros repertorios peninsulares y europeos. Como se verá más adelante, varios de los relatos proceden de los siglos XII-XIII, y fueron adaptados, traducidos y empleados en el siglo Xv con una finalidad catequética. Por ello, el estudio de los exempla del códice pamplonés se acomete asimismo teniendo en cuenta su dimensión histórica, como reflejo de la mentalidad y espiritualidad de la sociedad que los produjo y los empleó.

Por último, es necesario advertir acerca de las dificultades que entraña el empleo de sermones y otros textos relacionados con esta actividad, pues su vinculación con la realidad efectiva de su predicación o utilización puede ser muy remota. Se trata de fuentes indirectas para reconstruir la puesta en escena de la pronunciación de un sermón, aquella en la que intervienen el predicador

\footnotetext{
${ }^{8} \mathrm{El}$ otro códice con textos en navarro es el número 49: contiene cuarenta y cuatro homilías datables entre los siglos IX y XI y traducidas en el siglo XV al romance navarro, que han sido estudiadas y editadas parcialmente por diversos autores. En 1995, Fernando González Ollé editó cinco homilías en Sermones navarros medievales: una colección manuscrita (siglo XV) de la Catedral de Pamplona (Hardover, 1995), en 2000 Manuel A. Sánchez Sánchez publicó otra selección de seis textos en «De homiliarios medievales» (ob. cit., pp. 41-162), y en 2009 se publicó un nuevo estudio del códice y se editaron nueve homilías más: Beatriz Marcotegui, Instructio morum et fidei, ob. cit.
} 
y su auditorio 9 . La lengua, el contenido real del discurso, las estrategias de persuasión empleadas, el tono de voz, la reacción de los oyentes, el resultado final de la predicación: son elementos que no podemos conocer directamente a través de los textos que nos han quedado. Si se trata de sermones, en el mejor de los casos son versiones de un discurso, elaboradas posteriormente por un individuo que tal vez haya desvirtuado el mensaje transmitido y, por tanto, pueden no ser un reflejo fiel de la realidad. En el caso de otro tipo de textos como colecciones de relatos, de citas bíblicas o modelos de sermones, constituyen instrumentos de predicación, de manera que no podemos conocer cómo fueron utilizados, ni siquiera si verdaderamente fueron empleados. Aun y todo, con las debidas precauciones, constituyen una fuente valiosa para estudiar multiplicidad de aspectos de la sociedad medieval, como la introducción de nuevas devociones, las prácticas litúrgicas, los usos y comportamientos morales, así como la relación entre literatura y religión, entre cuentística y propaganda pastoral.

\section{El códice 48 de la Catedral de Pamplona}

El códice 48 mide 21 ' 15 centímetros de alto y 15 de ancho. Las tapas son de madera forrada en cuero y en la parte interna llevan un pergamino impreso que ha sido reutilizado para la encuadernación. El códice, que aún conserva un pasador, consta de ciento un folios de papel, y aunque todos ellos tienen dibujada una caja de escritura de 13'6 por 10 centímetros, estas medidas sólo son respetadas en los setenta y dos primeros folios; en adelante los márgenes son irregulares.

Tanto por su tamaño como por sus características, es un códice eminentemente práctico y manejable, compuesto con una orientación claramente funcional, y sin apenas decoración. Se trata de una completa y valiosa recopilación de textos y materiales para el desempeño de una labor de predicación. La parte más amplia y cuidada del manuscrito -y probablemente, la fundamental- es un repertorio de treinta y siete sermones latinos de tempore (ff. 3r-72r) al que el copista, tal vez con la finalidad de hacer más útil y completo el códice, añadió otros textos.

Así, a los sermones les sigue una pequeña colección de siete exempla escritos en navarro (ff. 73r-76v), en la cual se hallan intercalados dos sermones o colaciones también en este dialecto. Después, continúa un breve e interesante sermón sobre la Natividad de la Virgen (ff. 77r-78r), de nuevo

\footnotetext{
${ }^{9}$ Pedro M. Cátedra, Sermón, sociedad y literatura en la Edad Media: San Vicente Ferrer en Castilla (1411-1412), Salamanca, Junta de Castilla y León, Consejería de Cultura y Turismo, 1994, p. 84.
} 
en lengua latina. Los textos siguientes son apuntes de diversa procedencia y materiales útiles para una labor de predicación o para la formación religiosa, todos ellos escritos en latín: anotaciones del Antiguo Testamento (ff. 79r-78v y 80r-87r), una explicación de las siete peticiones de la oración del Padre Nuestro (f. 79v), una breve disertación sobre las obras de misericordia hacia los difuntos (f. 95r), citas del Compendium Theologicae veritatis ${ }^{10}$ (ff. 95v$98 \mathrm{v})$ y, finalmente, una serie de apuntes de sermones o una breve colección de citas de distintos autores (ff. 99v-101v). Por último, en el interior de este códice se encontraba, sin formar parte de él, un sermón sobre el matrimonio escrito en el siglo XVI.

Cabe destacar la reiterada presencia del romance navarro a lo largo del manuscrito, lo cual hace bastante probable que hubiera sido efectivamente empleado por un predicador para preparar sus alocuciones. No hay que olvidar que el latín era una lengua internacional comprensible en toda Europa, y escribir ese códice en romance suponía reducir considerablemente su difusión. Parece lógico, por tanto, presuponer la rentabilización de ese esfuerzo de copia o traducción mediante una efectiva y frecuente utilización del manuscrito. De hecho, además de los exempla, en el verso del primer folio del manuscrito hay unas breves oraciones contra varias enfermedades -lamparones, lombrices, "epidemia", dolor de cuello y "mal de corazón"-, que combinan el dialecto navarro con fórmulas latinas y hebreas. A juzgar por el tipo de letra empleada, se puede datar el códice en la segunda mitad del siglo XV. Esta teoría parece ratificarse con el estudio de las filigranas o marcas del papel, que remiten a las décadas de los setenta u ochenta de esta centuria ${ }^{11}$.

De todos modos, el texto parece tener mayor antigüedad, pues la Biblioteca Municipal de Toulouse conserva un sermonario anónimo del siglo XIV muy similar al que aquí se estudia ${ }^{12}$. El manuscrito tolosano es más extenso y contiene cincuenta y siete textos, que abarcan todas las ocasiones de tempore, aunque con algunas omisiones. Sin embargo, el códice 48 de Pamplona no es

\footnotetext{
${ }^{10} \mathrm{Tal}$ vez se trate del Compendium Theologicae veritatis de Hugo Repelin de Estrasburgo, que curiosamente se conserva en el códice 2 de la Biblioteca de la Catedral de Pamplona, escrito hacia 1268.

${ }^{11}$ Todos los folios llevan como marca la figura de una mano, excepto a partir del sexto cuadernillo (últimas 21 páginas), donde cambia a una cruz de San Andrés. Se trata de filigranas muy similares a otras registradas por C. M. Briquet. Así, la de la mano del códice 48 es muy parecida a los modelos no 11152 y 11154, ambos de origen italiano, piamontés o genovés, de los años 1482 y 1473 , respectivamente. En cuanto a la cruz de San Andrés, parece coincidir con el modelo $\mathrm{n}^{\circ} 5721$ de Briquet, que pertenece al centro u oeste de Francia, del año 1486. Vid. Charles M. Briquet, Les filigranes. Dictionnaire historique des marques du papier dès leur apparition vers 1282 jusqu'en 1600, Leipzig, Hiersemann, 1923, II, pp. 335-336 y III, pp. 563-567.

${ }^{12}$ Toulouse, Bibliothèque de la ville, 876 , ff. 1r-84r. Schneyer publicó un catálogo de este manuscrito: Cfr. Johannes B. Schneyer, Repertorium der lateinischen Sermones des Mittelalters: für die Zeit von 1150-1350, Münster, 1969-1990, IX, pp. 611-616.
} 
una colección completa: compuesto tan sólo por treinta y siete sermones, la serie se interrumpe en el domingo decimosexto después de Pentecostés. De todas maneras, parece que el original que sirvió de modelo al códice pamplonés no fue el de Toulouse, pues se aprecian diferencias sustanciales en el contenido. Además, llama la atención que el copista del códice pamplonés termine la colección con la palabra explicit, lo cual hace pensar que el modelo original también se interrumpía en ese punto.

Se desconoce el autor de esta colección de sermones, que permanece anónima, si bien el modo de enunciar las fiestas litúrgicas es el propio de un fraile perteneciente a la orden franciscana ${ }^{13}$. Escritos en lengua latina, los sermones siguen la estructura establecida por las Artes praedicandi de la época. Así, el punto de partida es generalmente un fragmento del Evangelio del día, que se enuncia seguido de una explicación del mensaje general del sermón y del interés que despierta. A continuación, se divide el contenido del sermón en varias partes que posteriormente se desarrollan siguiendo una estructura arbórea. Se trata de sermones exegéticos, que interpretan las alegorías bíblicas en sentido moral y antropológico, de modo que no son textos de gran dificultad teológica.

\section{Una colección de exempla en navarro}

En el folio $73 \mathrm{r}$ comienza una pequeña colección de relatos ejemplares escritos en romance navarro. Exempla es el título que el copista otorga al repertorio, si bien se hallan intercalados dos sermones o colaciones -también en navarro- aparentemente destinados a una comunidad de cofrades. Por tratarse de textos que pertenecen a un género literario distinto no se estudiarán en este artículo, si bien no hay que perder de vista que el copista los copió entre el primer y el segundo exemplum porque existiría alguna relación entre ambos tipos de textos, bien temática o bien práctica, o porque tal vez los relatos se emplearon para ilustrar las colaciones.

El último exemplum -número 7- está incompleto, pues en algún momento se recortaron tres folios del cuadernillo, concretamente los que se hallaban detrás del folio 76. De ellos se conservan únicamente los márgenes izquierdos, de alrededor de un centímetro de ancho. Probablemente, estos contendrían el final del exemplum, e incluso alguno más, pues en el margen de la

${ }^{13}$ Los franciscanos toman la fiesta de Pentecostés, el domingo de Epifanía y el domingo de Resurrección como punto de referencia para enunciar los siguientes domingos, mientras que los dominicos lo hacen a partir de la fiesta de la Trinidad, la octava de Epifanía y la octava de Pascua. Vid. Maura O'Carroll, «The Lectionary for the Proper of the Year in the Dominican and Franciscan Rites of the Thirteenth Century», en Archivum Fratrum Praedicatorum, 49 (1979), pp. 79-103. 
primera de estas hojas, hacia la mitad, se puede leer la siguiente rúbrica: exemplum $m[a r] t[y r] i s$ (?) Probablemente, esta indicación marcaba el inicio de un relato y, a juzgar por su posición en el folio, se puede determinar la extensión del fragmento que falta al séptimo exemplum en aproximadamente veinte líneas -las correspondientes a un espacio de alrededor de 8' 5 centímetros de alto y 11 ' 5 de ancho-.

A diferencia de la colección de sermones, no existen marcas visuales que distingan unos relatos de otros ni tampoco numeración, si bien los dedicados a la Virgen María están diferenciados con unas rúbricas en el margen izquierdo -exempla número 2, 5 y 6-. A lo largo del texto se observan algunos tachones, equivocaciones y añadidos, por lo cual parece poco probable que se trate de una copia. Además, está escrito en su totalidad con tinta negra, y no se usan otros colores para subrayados o rúbricas, como sucede en los sermones del mismo códice. Asimismo, los textos carecen de decoración: el copista se limitó a escribir los exempla, sin detenerse en detalles. Sin embargo, hay que resaltar que en todos los textos, salvo el primero, falta la inicial de la primera palabra, y en su lugar hay un espacio en blanco, donde probablemente el copista tenía previsto añadir posteriormente una inicial orlada.

La singularidad de estos exempla no son las historias en sí mismas, que parecen corresponderse con textos muy difundidos y conocidos, sino el hecho de que en algunos casos se relaten con profusión de detalles y de manera muy desarrollada ${ }^{14}$. Así, por ejemplo, el primero de los exempla es una versión extendida del relato $\mathrm{n}^{\circ} 113$ del Tractatus de diversis materiis praedicabilibus de Étienne de Bourbon, dominico e inquisidor francés que murió en 1256. Este tratado está organizado en cinco partes, a las que probablemente les faltan otras dos que nunca llegaron a componerse; de esta manera, las siete partes se corresponderían con los siete dones del Espíritu Santo ${ }^{15}$. El relato 113 De matre sacerdotis apparente succensa está contenido en la primera parte De dono timoris. En el texto del dominico, un sacerdote pide en oraciones que se le muestre el estado en el que se encuentra su difunta madre, y ésta se le aparece sufriendo los tormentos del infierno, y le indica que es inútil que siga rezando por su alma, que ya está condenada. Pues bien, el exemplum del códice 48 es mucho más extenso, pues relata con detalle los adulterios y crímenes que cometió esa mujer, así como los ayunos y oraciones que, en lugar de la

${ }^{14}$ Debo agradecer a la profesora María Jesús Lacarra (Universidad de Zaragoza) la ayuda prestada para identificar los relatos de la colección. Igualmente, ha resultado fundamental para su localización la consulta de la base de datos on line, Thesaurus Exemplorum Medii Aevi (ThEMA): < http://lodel.ehess. $\mathrm{fr} / \mathrm{gahom} /$ thema/ $>$.

${ }^{15}$ Étienne de Bourbon, Tractatus de diversis materiis predicabilibus. Prima Pars, ed. de Jacques Berlioz y Jean-Luc Eichenlaub, Turnhout, Brepols, 2002, p. 124. 
confesión, ella realizó en vida con la esperanza de salvar su alma: «Porque fize dos pecados quando vuestro padre fue ultra mar. Por esto me tiran estas dos culuebras destas dos tetas e la III ${ }^{\mathrm{a}}$ por la boca, porque non manifesté a mi confessor aquellos pecados de mientre que podía con mi voca». También, existe un relato parecido en la obra De universo de Guillaume d'Auvergne, que vivió entre 1180 y $1249^{16}$.

Además de este primer texto de la colección, en el códice 48 se incluyen otros dos relatos emparentados con el tratado de Étienne de Bourbon y pertenecientes a la tercera parte de su obra De dono sciencie: el tercero - que coincide con el no 1006 De vidua accusata - y el séptimo -versión simplificada de la leyenda de Roberto el Diablo, recogida en el relato $n^{\circ} 939$ De penitentia Robertis- ${ }^{17}$.

Así, el tercer exemplum trata sobre una condesa viuda que mantuvo relaciones incestuosas con su hijo y quedó embarazada. Cuando nació el hijo fruto de esa unión, lo ahogó para que nadie supiera de su pecado. Sólo el diablo se enteró del suceso: se disfrazó de religioso y acusó públicamente a la mujer de su crimen. La autoridad competente fijó la fecha del juicio para más adelante, tiempo que aprovechó la protagonista para confesarse y hacer penitencia. De este modo, cuando llegó el día del juicio, el diablo no encontró nada que reprochar a la condesa y se vio obligado a huir del pueblo. Este relato es muy semejante al que ofrece Étienne de Bourbon. De todas maneras, existen otras muchas versiones y en ellas es la Virgen María la que protege y conduce a la confesión a la condesa, que no interviene en la versión navarra. Por lo tanto, este exemplum de la Catedral de Pamplona debe incluirse entre la serie de versiones de la historia de "la burguesa de Roma"18. Entre ellas, cabe destacar la de Vie des Pères de Henri D'Arci, un repertorio de relatos en verso compuesto durante la segunda mitad del siglo XIII ${ }^{19}$. Igualmente, este cuento figura en la literatura ejemplar hispana, aunque también protagonizado por la Madre de Dios; cabe destacar, por su mayor proximidad al exemplum estudiado, la versión de las Cantigas de Santa María, compuestas durante el reinado de Alfonso X el Sabio entre 1252 y 1284, y la del Libro de los exemplos por $A B C$ de Clemente Sánchez de Vercial -redactado entre 1400 y $1420-^{20}$.

${ }^{16}$ Ibidem, p. 426.

${ }^{17}$ Étienne de Bourbon, Tractatus de diversis materiis predicabilibus. Tertia Pars, ed. de Jacques Berlioz y Jean-Luc Eichenlaub, Turnhout, Brepols, 2006, pp. 34-36 y 102.

${ }^{18}$ Ibidem, p. 466.

${ }^{19} \mathrm{Cfr}$. Jean-Charles Payen, Le motif du repentir dans la littérature française médiévale (des origines à 1230), Ginebra, Droz, 1967, pp. 522-524.

${ }^{20}$ El exemplum 3 de la colección se corresponde con el 274 (205) del Libro de los exenplos de 
El séptimo relato también está emparentado con el $n^{\circ} 939$ del tratado de Étienne de Bourbon. Como se ha dicho anteriormente, este texto no está completo en el códice navarro, de manera que tan sólo se conserva el planteamiento de la historia. Se trata de un matrimonio que había prometido vivir en castidad. Pero un día la mujer se arregló y acicaló hasta el punto de que no pudieron cumplir su promesa y mantuvieron relaciones sexuales. Y el niño que nació de aquella unión lo ofrecieron al diablo. Pasados los años, cuando el hijo se enteró de lo sucedido fue a ver a un ermitaño, y en este punto queda interrumpido el relato. Parece tratarse de una versión simplificada de la leyenda de Roberto el Diablo, muy común en muchos ejemplarios ${ }^{21}$. La más extensa es la de Étienne de Bourbon, si bien la primera versión fue compuesta hacia finales del siglo XII o comienzos del XIII y en versos octosílabos. Esta historia fue pasada a la prosa a finales del siglo XV y fue recogida y traducida por muchos autores ${ }^{22}$.

Igualmente, el segundo exemplum es una versión de un cuento ya conocido. Tiene lugar en Alemania y trata sobre un joven que en tres ocasiones mantuvo relaciones sexuales con su hermana, quedando ésta embarazada en todas ellas. Como en el tercer relato, la muchacha ahogó a los hijos fruto de estas relaciones. Arrepentida, intentó suicidarse comiéndose tres arañas vivas y, para acelerar su muerte, se rasgó los pechos con un cuchillo. Sin embargo, en el último momento se encomendó a la Virgen, que se le apareció y le persuadió para que confesara su pecado. Ésta le obedeció e ingresó como monja en un convento. La versión más antigua de esta historia se encuentra en la Vitae fratrum de Gérard Frachet, escrita en 1256 probablemente en un entorno dominico y con la finalidad de resaltar la santidad de Jourdain de Saxe, general de la Orden de Predicadores entre 1222 y 1237; en efecto, en la versión original, la protagonista ingresa como monja por consejo del santo

\footnotetext{
Clemente Sánchez de Vercial (ed. de John E. Keller, Madrid, 1961), y se asemeja a la cantiga $\mathrm{n}^{\circ} 17$ de las Cantigas de Alfonso X el Sabio (ed. de Walter Mettmann (cantigas 1 a 100), Madrid, Castalia, 1986, pp. 102-104).

${ }^{21}$ Vid. Jacques Berlioz, «Les versions médiévales de l'histoire de Robert le Diable: présence du conte et sens des récits», en Le Conte. Tradition orale et identité culturelle, Actes des rencontres de Lyon (27-29 novembre 1986), ed. de Jean-Baptiste Martin, Lyon, Association Rhône-Alpes conte, Agence régionale d'ethnologie, 1988, pp. 149-165; Jacques Berlioz, «Deux figures de l'excès: Robert le Diable et Gilles de Rais», en Les Cahiers Gilles de Rais, Nantes, Éditions Joca seria, 1 (junio 1992), pp. 53-58.

${ }^{22}$ En la versión de Bourbon, un matrimonio con problemas para tener descendencia pidió un hijo al diablo, y fruto de esa unión nació Roberto. Desde pequeño, su comportamiento fue cruel y despiadado. Pasados los años, su madre le contó a Roberto el motivo de su perversidad, y éste acudió a Roma para confesarse con el Papa. Roberto fue enviado ante un ermitaño, quien le impuso duras y humillantes penitencias que acabaron por reconvertirlo. Tras combatir a los bárbaros, el rey le ofreció en matrimonio a su hija, pero Roberto rechazó la oferta y siguió al ermitaño en su vida apartada. Vid. Étienne de Bourbon, Tractatus de diversis materiis predicabilibus. Tertia Pars, $\mathrm{n}^{\circ}$ 939, ed. cit., pp. 440-442.
} 
dominico ${ }^{23}$. No obstante, más cercana al exemplum de Pamplona es la versión de Vie des Pères de Henri D'Arci, donde también aparece el general Jourdain: se desarrolla en Alemania y trata de una mujer que se quiso suicidar tras haber matado a tres hijos suyos, nacidos fruto de relaciones sexuales con su tío ${ }^{24}$. También, esta historia aparece en las Cantigas de Santa María, aunque con algunas variantes ${ }^{25}$. Asimismo, este relato se recoge en un repertorio redactado a comienzos del siglo XIV y titulado Dits de Jehan de Saint-Quentin, escrito igualmente en verso ${ }^{26}$. De todas maneras, tampoco es éste el modelo directo del exemplum estudiado, pues se aprecian algunas diferencias.

El cuarto exemplum cuenta la leyenda de San Ermengol, obispo de Urgell entre 1010 y 1035 y que murió accidentalmente al caer al río Segre durante la construcción del puente de Bar. Durante su episcopado, Ermengol promovió la construcción de varias iglesias y puentes ${ }^{27}$, si bien el relato de la Catedral de Pamplona explica estas iniciativas como una manera de expiar su tendencia lujuriosa, lo cual no es recogido por ninguna otra versión ${ }^{28}$ :

Sant Emergant obispo de Urgel tanto era luxuriosso que si traspasasse tres días que no obiesse part con muger luego meaba sangre. E por este pecado que fazía tan grant, mucho dejunaba et fazía almosna quanto más podía (f. 75r).

No se ha conservado el relato hagiográfico original de San Ermengol Vita sancti Ermengaudi- escrito pocos años después de su muerte (entre 1042 y 1045). Las versiones más tempranas de esta Vita son del siglo XIII y del XIV.

${ }^{23}$ Jehan de Saint-Quentin, Dits en quatrains d'alexandrins monorimes, ed. de Birger M. Olsen, París, Societé des Ancien Textes Françaises, 1978, pp. XC-XCVI.

${ }^{24}$ Cfr. Jean-Charles Payen, Le motif du repentir, ob. cit., pp. 519-522.

${ }^{25}$ Alfonso X el Sabio, Cantigas de Santa María, n 201, ed. de Walter Mettmann (cantigas 101 a 260), Madrid, Castalia, 1988, pp. 244-246.

${ }^{26}$ Esta colección, redactada por un autor desconocido, contiene 24 relatos en cuartetos de alejandrinos monorrimos. También, en esta obra se recoge un relato similar al tercer exemplum del códice 48 (Jehan de Saint-Quentin, Dits en quatrains d'alexandrins monorimes, ed. cit., pp. 39-46).

${ }^{27}$ San Ermengol comenzó la construcción de la catedral de Santa María de Urgell, consagrada en 1040, e hizo edificar la iglesia de San Miguel Arcángel, cerca de la catedral. Ninguna de estas dos iglesias se conservan actualmente. También, consagró la iglesia de Sant Julià de Coaner (1024) y la del monasterio de San Pedro de la Portella (1035), donde fundó una cofradía. Asimismo, desplegó una importante labor social, encaminada a mejorar las vías de comunicación y mejorar las condiciones de vida de los pueblos. Vid. Mathias Delcor, «Ermengol, evêque d'Urgell et son oeuvre (1010-1035), de l'Histoire à l'Hagiographie», en Les cahiers de Saint-Michel de Cuxa, 20 (1989), pp. 161-190; Cebrià Baraut, Jesús Castells, Benigne Marquès y Enric Moliné, «Episcopologi de l’Església d’Urgell, segles V-XXI», en Urgellia, 14 (1998-2001), pp. 40-41.

${ }^{28} \mathrm{Cfr}$. Cebrià Baraut, «Les fonts documentals i hagiografiques medievals de la vida i miracles de sant Ermengol, bisbe de Urgell (1010-1035)», en Urgellia, 14 (1998-2001), pp. 137-166. 
De todas maneras, esta historia concuerda con un nuevo modelo de santidad que se desarrolló en torno a los siglos XI y XII, paralelamente al impulso de las peregrinaciones a Santiago: la del santo constructor entregado a la atención de los peregrinos. En este sentido destacan Santo Domingo de la Calzada $(\dagger$ 1109), San Lesmes de Burgos († 1110), San Juan de Ortega († 1163), o San Gonzalo de Amarante $(\dagger 1260)$, y fuera del territorio peninsular, San Raimundo Gairard († 1118) y San Benezet de Aviñón († 1184) $)^{29}$.

El quinto exemplum narra la historia de una doncella muy devota de la Virgen, por la que había hecho un voto de castidad. Sin embargo, había un mancebo que la pretendía; ayudado de una vieja alcahueta, hizo peligrar su voto, tentándola y agasajándola con canciones y regalos, y consiguió que accediese a citarse con él. Mientras la muchacha esperaba a su enamorado, se arrepintió profundamente de lo que estaba dispuesta a hacer y comenzó a rezar a la Virgen María pidiéndole auxilio. Mientras tanto, el joven la espiaba detrás de un arbusto y fue testigo de cómo la Madre de Dios se le apareció a la doncella con toda su corte celestial. Impactado por esta visión, decidió respetar a la joven y ambos prometieron ingresar en una orden religiosa en servicio de la Virgen. Por el momento, no se ha encontrado un relato idéntico a éste. De todas maneras, en la literatura hispana se cuenta con historias semejantes; así, la primera parte del relato guarda paralelismos claros con La Celestina o con el cuento 13 de Sendebar ${ }^{30}$.

Igualmente, el sexto texto es muy conocido y difundido, tal y como demuestra el Index exemplorum de Frederic C. Tubach ${ }^{31}$. Cuenta la historia de un caballero devoto que solía rezar diariamente a la Virgen María. El diablo, deseoso de alejar al protagonista de esta buena práctica, se encarnó en forma de escudero para conducirle por el mal camino, y estuvo a su servicio durante tres años. No obstante, el protagonista tenía por amigo a un ermitaño, que pronto reconoció al diablo y éste tuvo que huir. Para expiar sus pecados, el caballero hizo penitencia en el desierto. Parece una versión muy cercana al relato 220 (libro III, cap. 24) del Liber de introductione loquendi del dominico Filippo de Ferrara, compuesto entre 1321 y 1347 para servir de guía de conducta a sus hermanos de la orden ${ }^{32}$. Curiosamente este repertorio tam-

${ }^{29}$ Vid. Soledad de Silva y Verástegui, «Los sepulcros de los santos constructores del Camino a Santiago de Compostela», en Los caminos de Santiago. Arte, Historia y Literatura, coord. de M. Carmen Lacarra Ducay, Zaragoza, IFC, 2005, pp. 129-167.

${ }^{30}$ Sendebar, ed. de María Jesús Lacarra, Madrid, Cátedra, 1989, pp. 118-120.

${ }^{31}$ Este exemplum se corresponde con el ${ }^{\circ} 1558$ del índice de Frederic C. Tubach (Index exemplorum: a Handbook of Medieval Religious Tales, Helsinki, Suomalainen Tiedeakatemia, 1981, p. 128).

${ }^{32}$ Silvana Vecchio, «Il Liber de introductione loquendi di Filippo da Ferrara», en I castelli di Yale, III (1998), pp. 131-138. 
bién contiene una versión de la leyenda de Roberto el Diablo, presente en el séptimo exemplum de la colección navarra.

Las colaciones intercaladas en la colección ejemplar guardan una relación temática con los exempla. La primera de ellas advierte de la necesidad de practicar obras de misericordia para salvarse, idea que es ilustrada con el ejemplo del obispo de Urgell. La segunda colación insiste en las ventajas de la pertenencia a una cofradía, entre ellas, la salvación del alma y la fortaleza frente al diablo, temas tratados reiteradamente a lo largo de los relatos.

\section{Los exempla como recurso retórico}

Los exempla eran un instrumento muy frecuente y eficaz, empleado por los predicadores cuando se dirigían a audiencias populares y tenían que adaptar su discurso a sus particulares circunstancias socioculturales: no sólo les permitían apelar a la imaginación del oyente y atraer así la atención de los fieles, sino que también constituían una herramienta altamente persuasiva que ayudaba a convencer y conmover al auditorio. A diferencia de las similitudines o comparaciones con la vida cotidiana, el exemplum es un relato breve de un suceso singular perteneciente al pasado y del que se puede extraer una enseñanza ${ }^{33}$.

Los exempla estudiados reflejan una serie de temas muy propios de la espiritualidad bajomedieval, tales como la necesidad del sacramento de la confesión y de hacer penitencia para alcanzar la salvación eterna, o la consideración de la Virgen María como mediadora e intercesora de los pecadores ante Dios. Como antítesis del Bien, otro elemento constante en los relatos ejemplares y en la predicación medieval es el diablo, cuyo único propósito es conducir al hombre por el camino del pecado y alejarlo de Dios.

Según parece, la predicación bajomedieval se esforzaba por advertir al hombre de su responsabilidad sobre su comportamiento y el destino final de su alma. Según la mentalidad de entonces, el hombre era concebido como homo viator, que pasa por esta vida transitoriamente hacia un destino eterno, que será distinto en función del camino elegido. Por ello, los predicadores recordaban a sus oyentes los instrumentos con los que contaban para no sucumbir al pecado y llevar una vida que les condujera a la salvación eterna de su alma.

Los sacramentos, y concretamente el de la confesión, constituían una vía de salvación, especialmente desde que el IV Concilio de Letrán (1215)

\footnotetext{
${ }^{33}$ Claude Bremond, Jacques le Goff y Jean-Claude Schmitt, L'exemplum, Turnhout, Brepols, 1982, p. 83.
} 
estableciera la obligación para todos los fieles de confesarse una vez al año. La administración de este sacramento no se realizó siempre de la misma manera: así como en siglos anteriores se daba más importancia a los actos penitenciales, los teólogos bajomedievales insistían en la penitencia interior, en la contrición o dolor de corazón por haber pecado y en la vergüenza y humillación que suponía la confesión oral, particular y secreta, que también contribuía a la expiación ${ }^{34}$.

En este sentido, los exempla del códice 48 resultan muy representativos, e ilustran la necesidad de contar al confesor todos los pecados para recibir el perdón divino por ellos. Así, de nada sirvieron a la adúltera del primer exemplum las penitencias, oraciones y el arrepentimiento que mostró, ya que «nunqua confessó aquellos pecados de miedo de perder su fama». De hecho, no sólo recibió un castigo por su adulterio, sino también otro específico por el hecho de habérselo ocultado a su confesor: «por esto me tiran estas dos culuebras destas dos tetas e la III ${ }^{\mathrm{a}}$ por la boca, porque non manifesté a mi confessor aquellos pecados de mientre que podía con mi voca» (f. 73r).

La vergüenza por hacer públicos (y confesar) los pecados cometidos se encuentra presente en los tres primeros relatos de la colección, lo cual lleva a sus protagonistas a condenar eternamente su alma. Así, en el segundo exemplum se cuenta la historia de una joven que cometió incesto en tres ocasiones, pero no quiso confesar su pecado «de verguenca que obo». Angustiada, intentó suicidarse, si bien finalmente invocó a la Virgen, que se le apareció y le mostró la utilidad de la confesión como remedio contra el pecado: «"o tu loca e peor de loca, ¿por qué non te confessaste e no tomaste penitencia por que fuesses suelta? Sepas que si tu bas a tu cappelán e te confiessas e tomes penitencia, serás suelta"» (f. 74v).

Las lágrimas, como manifestación externa del dolor de corazón, también son habituales en los exempla de la colección. Como se ilustra en el tercer relato, para conseguir el perdón de Dios por los pecados cometidos era necesario confesarlos oralmente, con compunción y contrición, y hacer penitencia por ellos: «confessose bien, repentiendo e plorando e diolle penitencia». Por eso el diablo no encontró motivos por los que acusar a la protagonista en el juicio público que se celebró por su pecado.

Igualmente sucedió con Ermengol, obispo de Urgell, cuya vida se relata en el cuarto exemplum. De acuerdo con el relato, el prelado contrarrestó sus inclinaciones lujuriosas con una vida de penitencia y de servicio a los demás,

\footnotetext{
${ }^{34}$ Nicole Bériou, «Autour de Latran IV (1215): la naissance de la confession moderne et sa diffusion», en Pratiques de la confession. Des pères du désert à Vatican II. Quinze études d'Histoire, París, Cerf, 1983, pp. 76-79.
} 
construyendo y financiando puentes para uso público, y así alcanzó la santidad y el perdón de Dios por sus pecados. Precisamente murió durante la construcción de uno de esos puentes. Cuando se despeñó, varios de los que estaban presentes hablaron mal de él, creyendo que estaría en el infierno penando por su lujuria: «"baya agora el obispo fornicador al infierno, ay trobará muchas putas e fará fornición quanto quisiere"». Sin embargo, el obispo era santo, como se demostró a través de un milagro que obró después de muerto, al resucitar a un niño cuyo cadáver fue puesto sobre el cuerpo del difunto Ermengol. Su vida dedicada a la caridad y a la penitencia compensó las tendencias pecaminosas del prelado.

Otro elemento presente en los exempla de la colección navarra y que constituían una constante en el discurso de los predicadores es el llamamiento a la oración a la Virgen María, en petición de ayuda y de protección frente al Mal. La devoción a María experimentó un importante desarrollo en los últimos siglos medievales, especialmente a partir del siglo XI, gracias al impulso de San Bernardo y la orden cisterciense ${ }^{35}$. San Bernardo fue un gran cantor de las virtudes de María, especialmente la virginidad y la humildad, que junto a otras como la misericordia o la ternura, la presentaban muy cercana y accesible a los hombres. Precisamente, los últimos siglos bajomedievales se caracterizaron por una piedad cristológica, que exaltaba el lado más humano y sufriente de Jesús y ensalzaba la figura de la Virgen como madre de Dios y de todos los pecadores, como intercesora y abogada de los hombres ante su hijo Jesucristo. Por ello, en esta época se difundieron una gran cantidad de milagros protagonizados por María, donde se subrayaba su papel salvífico. En España, en el siglo XIII, cabe destacar los Milagros de Nuestra Señora de Gonzalo de Berceo, las Cantigas de Santa María de Alfonso X el Sabio o el Liber Mariae del franciscano Juan Gil de Zamora.

Resulta especialmente significativo el quinto exemplum, donde la oración a María se revela como la mejor manera de ahuyentar el Mal y la tentación. Cuenta la historia de una doncella que, tentada por los encantos de un joven, vio peligrar su voto de virginidad, por lo que pidió protección a la Virgen María, y durante su oración ésta se le apareció. El relato ofrece una descripción plástica de la madre de Dios: de rostro hermoso, con una corona en la cabeza, que simboliza su estatus triunfante en el Cielo, acompañada de una luz resplandeciente y rodeada de una corte de hermosas doncellas y ángeles que cantaban una dulce melodía:

${ }^{35}$ Ann-Katrin Johanson y Éric Palazzo, «Jalons liturgiques pour une histoire du culte de la Vierge dans l'Occident latin ( $\mathrm{V}-\mathrm{XI}^{\mathrm{e}}$ siècles)», en Marie: Le culte de la Vierge dans la société médiévale, comp. de Dominique Iogna-Prat, Éric Palazzo y Daniel Russo, París, Beauchesne, 1996, pp. 16-18. 
e vio los ciellos aviertos e venir la madre de Dios con los ángeles, e la su cara delectable era de ver. La su corona resplandecía e todo el ayre. Assentose cerca la donzella e pusso su mano sobre ella e las vírgines fazíanle cort derredor. Eran más fermosas que el sol ni la luna, e cantaban más dolcament que nigún istrument (f. 76r).

Estos elementos son constantes en los relatos hagiográficos de las apariciones de los santos, especialmente la luz, símbolo de la gloria de la que participan y de su beatitud ${ }^{36}$. Esta manifestación gozosa de la Virgen transforma el entorno y crea un ambiente agradable a los sentidos: a la vista, por la belleza y el resplandor glorioso; al oído, por los cantos celestiales; y quizás también al olfato, pues se les atribuía a los santos la cualidad de desprender un agradable perfume -odor sanctitatis-. Concretamente, según varios visionarios medievales, la Virgen desprendía un aroma de rosa y azucena, símbolo de su pureza ${ }^{37}$. También, la hermosura de la Virgen es una constante en los relatos de apariciones marianas, que no puede compararse con nada en este mundo y de la que, según el relato, participan la corte de vírgenes santas que le acompañan.

Con este exemplum el predicador animaba a la práctica ordinaria de la oración a María, pues todo aquel que se encontrara en peligro e invocara el cuidado de la Virgen, recibiría su auxilio. La doncella «clamó la ayuda de santa María fincando los genollos», es decir, de rodillas. Esta postura genuflexa con ambas rodillas representa la postura de oración que se difundió a partir de los siglos XI y XII en la cristiandad occidental, en un acto de humillación ante Dios, de adoración y de penitencia. Anteriormente, el principal gesto de oración era permanecer de pie con las palmas hacia arriba o con los brazos en cruz, imitando la posición de Cristo durante su Pasión ${ }^{38}$.

La muchacha tenía la costumbre de rezar también por los muertos: «sollía decir las oras de Santa María cada día con obsequia defuntorum» (f. 75v). Por ello, cuando la joven estuvo en apuros y pidió ayuda celestial, los difuntos le prestaron su protección: «mientre que ella decía los obsequios, los muertos humiliánseli delant con grant devoción». Se trata de la comunión de

\footnotetext{
${ }^{36}$ Ángeles García de la Borbolla, La "praesentia" y la "virtus": la imagen y la función del santo a partir de la hagiografía castellano-leonesa del siglo XIII, Santo Domingo de Silos, Abadía, 2002, pp. 113-118.

${ }^{37}$ Sylvie Barnay, Le ciel sur la terre: les apparitions de la Vierge au Moyen Âge, París, Cerf, 1999, p. 152.

${ }^{38}$ Jean Claude Schmitt, La raison des gestes dans l'Occident médiéval, París, Gallimard, 1990, pp. 289-301.
} 
los santos, en la cual el hombre medieval tenía puesta su confianza: los vivos (iglesia militante) cumplen con las obligaciones contraídas con sus antepasados difuntos (iglesia purgante) rezando y celebrando misas, mientras que aquellos que ya han alcanzado la gloria de Dios (los santos o iglesia triunfante) pueden interceder por Dios ante los hombres.

Por último, otra figura que nunca falta en los sermones medievales es el diablo, que encarna el Mal y cuyo único objetivo es persuadir a los hombres para desviarlos del camino de la virtud y conseguir la condenación eterna de su alma. Así lo confiesa el propio diablo en el sexto exemplum de la colección: "“Mandado me era que si huna vez cessase de la oración de día e de noche, que lo matasse e lo lebasse al infierno"» (f. 76v). En este relato se subraya la impiedad del demonio, que está al acecho para matar al hombre en cuanto peque, sin dejarle tiempo para arrepentirse y volver a Dios.

Los predicadores advertían del gran poder de persuasión del diablo y de la astucia con la que embauca a los hombres, recurriendo a mentiras y engaños. Por ello, en la literatura medieval es muy habitual que el diablo adopte distintos aspectos y apariencias amables ${ }^{39}$. Como conoce las debilidades y necesidades de cada uno, sabe cuál es la mejor manera de abordar a cada fiel. Así, en el relato sexto, protagonizado por un caballero, el diablo se disfraza de escudero y asegura poder guiarle por los caminos de manera eficaz, excepto en el que conduce hacia Dios: «vénole en figura descudero e díxole que sabía todos los passos daquella tierra e los ganados e los castillos». También es destacable la obstinación del diablo, dedicado durante tres años y con diferentes tretas a desviarle de su práctica ordinaria de rezar a la Virgen. Como se dice al inicio del exemplum, «Sathanás se traballó mucho destorbar».

Otra referencia interesante de este relato es la manera de presentarse el demonio como perteneciente a la compañía de Lucifer, bajo cuyas órdenes trabaja: "'Yo so dela companya de Lucifer e fue inbiado que lo engaynasse a este cavallero"». Así, se ofrece una imagen majestuosa del diablo, como rey soberano en su reino (el infierno) y que cuenta con una corte de demonios o malos espíritus que le obedecen y trabajan por sembrar el Mal. Esta iconografía era muy habitual en las representaciones y relatos diabólicos de los siglos XIV y XV, en consonancia con el desarrollo y esplendor de las cortes de las monarquías europeas ${ }^{40}$.

\footnotetext{
${ }^{39}$ Juan Antonio Ruiz Domínguez, El mundo espiritual de Gonzalo de Berceo, Logroño, Instituto de Estudios Riojanos, 1999, pp. 123-127.

${ }^{40}$ Jérôme Baschet, «Diable», en Dictionnaire raisonné de l'Occident médiéval, dir. de Jacques Le Goff y Jean-Claude Schmitt, París, Fayard, 1989, p. 271.
} 
En cuanto a su apariencia, a lo largo de la Edad Media se fue acentuando en la literatura y en el arte una imagen monstruosa del diablo y de su reino, el infierno: inicialmente se le representaba con una apariencia humana o humanoide, aunque escuálido y deforme, y desde el siglo XI comenzó a ser caracterizado con atributos animales como cuernos, hocico, orejas puntiagudas, cola $\mathrm{y}$, desde el siglo XIII, con alas de murciélago. Asimismo, muy frecuentemente se le relacionaba con elementos negativos, como el ruido, el fuego, el humo y el mal olor ${ }^{41}$. Así, en el tercer relato de la colección estudiada, el diablo regresa al infierno «echando fuego et flama».

El diablo es protagonista asimismo del tercer exemplum, donde se exalta su astucia, que no encuentra rival en sus disputas: «fue para la escuella e venció a todos los maestros en disputa». Además, el autor subraya que ninguno de los pecados del hombre pasa desapercibido a los ojos del Maligno, aun cometidos en secreto: «neguno no lo entendió mas el diablo, luego quando el Mal faze, sabe». Es destacable en esta historia la representación que se ofrece del juicio particular que tendrá lugar tras la muerte de cada fiel, y en el que el diablo actuará de parte acusadora ante Dios juez: el demonio es portavoz de la conciencia, y recopila los pecados cometidos en vida por los hombres para usarlos en el juicio como argumento para conseguir que el alma del fiel le sea entregada. El único modo de borrar esa memoria del diablo es mediante la confesión, el sacramento que limpia al hombre de pecado y lo devuelve a su estado de gracia.

Así, como en los juicios ordinarios, en este tercer relato el diablo se querelló contra la condesa protagonista, acusándola ante el alcalde de la villa de incesto y parricidio. El justicia tomó declaración a las partes en una primera comparecencia pública, y se fijó la fecha del juicio público para más adelante. En ese tiempo, la condesa protagonista aprovechó para confesarse con el obispo y cumplir su penitencia, de modo que cuando llegó el día del juicio el diablo fue incapaz de recordar el crimen que le había imputado y se quedó sin argumentos de acusación. Así que se vio obligado a huir y regresar al infierno: «començaron stigonar todos e fuyó el diablo luego echando fuego et flama».

Por lo tanto, en este relato se mezclan dos imágenes del diablo: una amenazante y terrorífica, como acusador, y otra cómica y burlesca, desmemoriado, perseguido por las gentes del pueblo. En realidad, estas dos facetas del demonio también se mezclaban en la vida ordinaria medieval, pues frecuentemente

\footnotetext{
${ }^{41}$ Jeffrey Burton Rusell, Lucifer. El Diablo en la Edad Media, Barcelona, Laertes, 1995, pp. 144148.
} 
las representaciones teatrales presentaban al diablo como un personaje ridículo y grotesco ${ }^{42}$.

$$
* * *
$$

En definitiva, los exempla analizados constituyen una fuente de gran valor. Como se ha visto, no estamos ante textos originales, pues son traducciones o adaptaciones de relatos ya conocidos y ampliamente difundidos, pero en ocasiones cuentan con una gran profusión de detalles, no recogidos por el resto de versiones. Lo más llamativo es el hecho de estar escritos en el dialecto navarro, lo cual permite suponer que el libro fue verdaderamente empleado, o al menos hace más probable su utilización dentro del ámbito del reino de Navarra. Asimismo, la colección tiene un indudable valor como reflejo de la espiritualidad bajomedieval y de los recursos empleados por los predicadores para hacer llegar el mensaje evangélico y las verdades de fe.

El sermón es un género con grandes contactos con otros campos de la Literatura, como la hagiografía o la literatura ejemplar, o incluso la sátira y el drama, y que desempeñó una función educativa de la sociedad y un papel importante en el desarrollo del lenguaje y del pensamiento. En concreto la relación entre sermones y exempla es esencial, pues la predicación constituyó un medio fundamental de difusión de los relatos ejemplares y, a su vez, su uso en este contexto posiblemente también estimuló y motivó su composición.

El sermón tenía una clara finalidad didáctica y persuasiva, lo cual provocó que el predicador buscara estrategias retóricas que aseguraran la eficacia de su discurso. Por ello, y de manera especial en la predicación destinada a las audiencias más populares y con menos formación, los símiles y los exempla jugaron un papel importante como pruebas inductivas de la argumentación del predicador, que permitían comparar las elevadas verdades teológicas con sucesos de la vida cotidiana y hacerlas más asequibles, así como exhortar, conmover y mover al auditorio a la adopción de un comportamiento moral correcto $^{43}$.

De este modo, en los siglos medievales el ejemplo se convirtió en una herramienta de gran utilidad, cuya fuerza no residía tanto en la veracidad de los hechos narrados como en su capacidad ilustrativa de la doctrina cristiana o del modelo de conducta promovido por el predicador. Por eso se conocen tantas versiones de los mismos exempla, cuyos protagonistas y sus comportamientos variaban según fuera la función que debía cumplir el relato dentro

${ }^{42}$ Ibidem, pp. 267-268.

${ }^{43}$ Sobre el exemplum como instrumento retórico al servicio de la predicación y la trayectoria histórica de su uso como prueba argumentativa, vid. Manuel Pérez, Los cuentos del predicador: historias y ficciones para la reforma de las costumbres en Nueva España, Madrid, Iberoamericana, 2011. 
del sermón. Asimismo, en los relatos tiene una fuerte presencia lo sobrenatural, lo cual no afectaba a su utilidad y eficacia argumentativa, ni tampoco a su verosimilitud, pues en la mentalidad medieval los límites de lo ordinario y lo extraordinario, lo natural y lo sobrenatural no estaban tan delimitados como actualmente. Los milagros, las apariciones, eran acontecimientos más o menos frecuentes, y se aceptaba que objetos y sucesos cotidianos, como las enfermedades, fueran o representaran signos visibles del Más Allá ${ }^{44}$.

\section{Edición de los exempla del códice $48 \mathrm{BCP}$}

\section{Exempla}

\section{[1: La adúltera que ingresó monja, f. 73r]}

Eran huna begada marido e muger, assí que el marido quiso yr Ultra mar e abían hun fijo scolano. Desó a la muger con su fijo e fue a Ultra mar. Otrosí el fijo fue entrado monge en huna orden. Cuando él fue en la orden ovo [tachado: age] a errar la madre con huna persona e fue preynada e parió. Quando fue parida tomó la creatura e mató e quando la obo muerta enterrola en el stable [tachado: la stabla]. Otra vegada obo a [tachado: (a)genar] errar con huna otra persona e fue otra vegada preynada e parió e afogó la creatura, scondiolla en el stablo.

E solía se confessarse en las tres pascoas e nunqua confessó aquellos pecados de miedo de perder su fama. Pensó assí de entrarse en huna mongía y que salbaría su ánima en aquella mongía con oraciones e con dejunos. Assí fizo. Entrubo con mucho algo e con mucha riqueza en la mongía e leva[n]tábasse a media noche a fazer oración a la yglesia e quando las otras monjas se leva[n]taban a maytinas sienpre fayllaban que jazía delant [tachado: sobr] el altar plorando. Sollía ajunar en la semana tres días, lunes, miércoles, biernes a pan y agoa. E dezían las dueynas entresí daquella dueyna que tan buena ajunadera era e tan debota de oraciones, que todas se marabejaban della.

Assí que huna noche levantosse al primer sueyno a la yglesia e sentosse delant el altar diziendo oraciones. Veno Sathanás e tomó huna sabbana del altar, pretole en la garganta e afogola, tomó la ánima e levó a los infiernos. Leva[n] táronse las dueynas a maytinas e fallaron [tachón] la dueyna que jazía muerta. Dixieron las dueynas por gracia de Dios qué podia ser aquello que Dios abía fecto aquell miraglo, que ella siempre que era buena dueyna, car ellas assí cuydaban que era buena.

Assí que el fijo suyo que era entrado monge acertosse que fue buen clérigo e fue [tachón] prior de la orden e missa cantano. E sopo la muerte de su madre cómo era finada e beno en aquell monasterio. Demandó de su madre e dixiéronli que era finada. Ploró mucho el fijo. Al otro día lebantosse grant maynana, dixo

${ }^{44}$ El hombre medieval, ed. de Jacques Le Goff, Madrid, 1990, p. 38. 
sus oras e quiso a Dios rogar en la missa que éll demostrasse la su gracia en éll por que sopiesse la ánima de su madre si era en paradiso o en purgatorio o en infierno. Él seyendo en tormento aparescioli la ánima de su madre teniendo dos culuebras en las dos tetas que la mordían e la tercera que entraba por la voca. Díxole el fijo: "madre, ¿cómo vos ba?" Respondió ella: "Fijo, ja ves qué mal". Dize: "madre, ¿por qué?". "Porque fize dos pecados quando vuestro padre fue ultra mar. Por esto me tiran estas dos culuebras destas dos tetas e la III ${ }^{\mathrm{a}}$ por la boca, porque non manifesté a mi confessor aquellos pecados de mientre que podía con mi voca. E fijo, digo vos assí que de mientra vos más rogare, tanto me dan mayores penas. $\operatorname{Exp}[$ licit $]$.

\section{[2: La joven que cometió incesto y quiso suicidarse, $f$. 74v]}

[En el margen: $s($ anct $) a m($ ari $) a$ ] Era en Alamania hun honbre joven e abía tres hermanas e moriéronsele las dos. Assí que jazió el joven con la tercera hermana et enpreynola de huna creatura. Esta mezquina parió en el establo e de verguenca que obo afogo la creatura e echola en la pribassa y este pecado le conteció bien tres vegadas. Vino hun día e de verguenca que obo, tomó tres araynas bibas de las paredes por tal que inflase e con aquella infladura moriesse. E assí lo fizo, comió las yraynas e infló e tomó hun cuchello e fincolo en terra e con los pechos dio en el cuchello por tal que moriesse mas ayna. Maguera con todo el mal que abía, dixo: "Sancta María me balga". Estonz vino Sancta María e díxole: "o tu loca e peor de loca, ¿por qué non te confessaste e no tomaste penitencia por que fuesses suelta? Sepas que si tu bas a tu cappelán e te confiessas e [tachado: te] tomes penitencia, serás suelta". E depués fuesse al capellán e confiessó bien e por consejo del confessor diosse a la orden e servió a Sancta María et fue salba.

\section{[3: La mujer que cometió incesto y el diablo que la acusó, ff. 74v-75r]}

Era hun fijo de hun conde e casó con huna fija de huna condessa et amábanse mucho como jóbenes et finó el marido e dessó preynada a su muger et parió fijo e todos días solía plorar por su marido. Quando vio que era fijo quitóseli la dollor del marido. Assí que por grant amor que obo del fijo criollo ella por sí con sus tetas, e sollía jazer con ella, e así fue crescido. Assí que hedat obo de peccar et [tachado: pequo] pecó con la madre et fue preynada la madre del fijo e obo de parir. E por miedo que lo sopiesse neguno, afogó la creatura et enterrólo en huna stablia. Neguno no lo entendió mas el diablo, luego quando el Mal faze, sabe.

En aquella villa abía grandes scuellas. Tomó bos el diablo forma de hun maestro, vino vestido como religiosso e fue para la escuella e venció a todos los maestros en disputa. Bien [tachado: ha] esto duro VIII ${ }^{\circ}$ dias. Sopo el mayor conde que era justicia de aquel logar e fue pora scuela e fue en la disputación. Fue allí el diablo e venció a todos. Quando los obo vencidos a todos dixo delant 
todos al caudiello que abía huna dueyna en aquella villa et que se querellaba della et que le fizié justicia. Assí que inbiaron por la dueyna. La dueyna fue allá con sus donzellas, entró dentro et asentáronse et callaron todos. Dixo el diablo: "esta dueyna es atal que hasció mal que fue preynada de su fijo e la creatura enterró en casa. Sto es assí et dat me drecho". Fue la dueyna en cueyta, no sabía qué dezir que todo era verdat. Maguera dixo assí: "ell era grant clérigo que lo acuse mal et diesse día de acuerdo et que ella respondría".

La dueyna fuesse luego al obispo et confessose bien, repentiéndose et plorando, et diolle penitencia, que ajunasse en pan e agoa a tal plazo que Dios daría consejo et que dixiesse oraciones quanto podía. Assí fizo: comía apart en huna cambra pan de ordio et agoa e solía dezir oraciones quanto podía. Et fue al plazo e beno ayllí grant gent por la fama que sallió, aún más que antes. Quando fue plegada la conpanya et ella y el diablo, dixo el justicia al diablo que se razonasse con aquella dueyna como abía dicto en antes mal por ella. Respondió el diablo que éll nunqua abía dicto nada por ella, mas que era buena dueyna ésta, que no quería dezir [tachado: tal cosa] mal por ella. Porfiaronli mucho que dixiesse ell jurado que ni dixo ni dixiera ni quería dezir tal cosa, que ella era sancta e buena. Entonz comencaron stigonar todos e fuyó el diablo luego echando fuego et flama et finco la dueyna quita por la penitencia. Tal cosa es penitencia.

\section{[4: Historia de San Ermengol, f. 75rv]}

Sant Emergant obispo de Urgel tanto era luxuriosso que si traspasasse tres días que no obiesse part con muger luego meaba sangre. E por este pecado que fazía [tachado: tro] tan grant, mucho dejunaba et fazía almosna quanto más podía. En aquell tiempo fizo fer huna puent en huna carrera por do abían a benir los de aquella ciudat, en que espendió mas de $\mathrm{X}$ mil morabidís, porque en aquell logar el fuert biento muchos hombres echava de la peyna en jusso, do abía bien diez mil scad. [?] Ell niguna cosa no abía, mas assí como pobre demandaba por todo su obispado e por todas casas las almosnas et fazía grandes perdones por amor de aquella puent.

Una otra puent fizo otrosí en más fuert logar do morían muchos cada día. Quando [tachado: nra.] en aquella puent demandó hun día el maestro que la fazía huna piedra e niguno de los obreros nolli dio e dixo: "el obispo me dé aquella piedra". El obispo, metiendo la piedra en su onbro, quísolo Dios e cayó con la piedra ajuso, do abía más de cient scad. [?] E los honbres quando oyeron, fablaron de su muert. E dezían: "baya agora el [tachado: opbo.] obispo fornicador al infierno, ay trobará muchas putas e fará fornición quanto quisiere”.

E quando vino la muert cuat [?] a que huna grant companya de ángeles en senblanca de candelas luzientes e cantaban muy dolcemente. Mas los honbres malos dizían que muchos diablos eran que se deportaban e cantaban sobre el 
obispo. Vinieron los clérigos e dixieron entressí: "muy mal fazemos que desta guissa dessamos el cuerpo e que no abemos cuydado de soterrarlo. Porque nuestro sennyor fue, vayamos et demandemos cuerdas e decendamos ad aquell logar do jaze el cuerpo e traygamos a su logar e honrradamente soterrémoslo". E descendieron estos clérigos assí como lo abían parado, levaron fuego por fazer signo. Quando abían dreçado el cue[r]po e quando esto obieron fecto, aquellos que estaban suso tiraron las cuerdas e sacaron el cuerpo et a ellos en los cuébanos.

E mietra que los clérigos lebaban el santo cuerpo del obispo, en la carrera encontraron a hunos honbres que lebaban a soterrar ha hun moço de doze aynos que era afogado en la agoa. E quando los clérigos vieron a este cuerpo retobiéronlo e dixieron a los otros que eran ay: "agora podremos conoscer si el alma deste obispo es con Dios o no". E pussieron al moco muerto e metiéronlo cerca el cuerpo del santo obispo, e tan ayna como ay fue puesto el moço, tan ayna lebantó sano e alegre. E los honbres dema[n]dáronli en qué manera se resucitó él. Díxolis: "quando morí [tachado: (mori)e] en la agoa los diablos me tomaron et lebábanme al infierno porque era desobedient a mi padre e porque grant mal lis había fecto. Mas quando era ya cerca el infierno veno sant Emergant con grant companya de ángeles et quítome a los diablos et tovome con sí. E catadlo, aquí esta cerca vos, sorriéndose de vos por que mal dixiestes dell".

Quando oyeron esto aquellos que lo scarnecién, con grant miedo feran sus pechos e rogaban plorando que lis perdonasse el mal que abían dicto del. E depués lebantó ad aquell logar e soterráronlo honrradament [tachado: ens.] en huna sepultura muy honrrada.

\section{[5: La doncella devota de la Virgen, ff. 75v-76v]}

[En el margen: Exemplum de virgine.] Una donzella virgen sollía dezir las oras de sancta María cada día con obsequia defuntorum e lo que obraba si era [?] [tachado: vesti. que ve.] que cosía vestimentas de yglesias. Ésta prometió virginidat goardar a Sancta María.

Mas hun mancebo amábala con ardient amor et como mucho le seguiesse, magnifestoli su coraçón. Ella con tan grant aspreza lo denostó e lo apartó de sí, que enfermeció. E los meqes [?] que venían no podían conoscer qué enfermedat abía. Veno huna vieja e díxole que dixiesse qué mal abía sin verguenca, si abía cosa que le podiesse aprovechar, dixo. Él dize: "no ay cosa en el mundo que me pueda baller. Mas huna persona ay que me podría baler e goarecer de todo mal, mas no li diría neguno porque es mas dura que la piedra e mas fuert que el fierro. E más rafez sería el gamiello de passar por el forado de la aguja que ella oyr las mis rogarias".

Dixo la vieja: "yo la tornaré mas blanda que la cera ante el fuego". Assí que descubrioli todo el fecto. Díxole ella: "levantad vos et alegrat vos e cantad 
debant ella e con esto vos enpeçará amar e goardat vos de fazer villanía contra ella. E quando vos cuydáredes ser menospreciado, tanto mas cresce el amor. Et comprat la más fermosa cinta [tachado: con] que podiéredes aver e yo le presentaré e la saludaré de vuestra parte. E quando tomare algunos donos de vos, yo le rogaré que vos ame". Assí fue que tanto quisso la vieja que le prometió que faría su voluntad. E la vieja asignoli hun prado en hun mont que li sperasse al mancebo e tanó la vieja al mancebo e díxole cómo le speraba la donzella. Quando lo oyó pesole mucho porque no podía yr luego.

La donzella, quando vio que no venía, repentiosse mucho porque quería fazer la deshonrra de su parie[n]te e perdía virginidat, et faría apessar de Dios et perdría paradisso e todo bien. Quisso se absconder, mas no podía fallar logar, que temíase de tornar que encontrase con el mancebo. E no sabía que fiziesse, e clamó ayuda de sancta María, e fincando los genollos enpecó [sic] dezir las [tachado: horr.] oras de santa María. E veno el mancebo e viola estar con grant devoción. El mancebo scondiosse que faría e vio los ciellos aviertos e venir la madre de Dios con los ángeles, e la su cara delectable era de ver. La su corona resplandecía e todo el ayre. Assentose cerca la donzella e pusso su mano sobre ella e las vírgines fazíanle cort derredor. Eran más fermosas que el sol ni la luna, e cantaban más dolcament que nigún istrument. La donzella no vio nada desto, mas el mancebo todo esto vio. Finidas las oras de sancta María partiéronse todas. La donzella pensando que faría, haun no era obiado el mancebo. Empeçó obsequia defuntorum et mientre que ella dezía los obsequios, los muertos humiliánseli delant con grant devoción.

Depués quando bio que non venía haún, asentosse sobre la yerba. E el mancebo veno a ella con grant miedo. Ella quando vio comencó plorar et díxole: "ruégote por la passión de Dios e por la su madre santa María que non te aplegues a mí más. Déssame yr mi carrera". El mancebo respondió con humil voz: "hermana, yo te prometo que nunqua te tocaré daquella manera, mas ruégote que me oygas hun poco, stándote apart". Et contolli lo que avía visto e prometieron ambos a la orden et quien quebratasse el dicto voto el huno al otro que lo acussase ante Dios el dia de juyzio. Et assí complecieron los dos lo que abían prometido e finaron en buena vida.

\section{[6: El caballero devoto de la Virgen, $f .76 v$ ]}

[En el margen: virgine]. Sathanás se traballó mucho destorbar [tachado: un] a hun caballero que sollía saludar a la gloriossa Virgen María y no pudo nada fazer en tres aynos, e vénole en figura descudero e díxole que sabía todos los passos daquella tierra e los ganados e los castillos. Quando esto oyó el cavallero rogole que fincasse con éll. E fincó con él en III ${ }^{\text {es }}$ annyos e no pudo fazer olbidar la oración, mas fízole fazer más de mal que no ante. 
Mas abía hun hermitano por amigo e conbidólo hun día e como se asentassen a la mesa e conosció al diablo que servía e conjurólo de parte Dios que le dixiesse verdat quién era o cómo fincaba con el cavallero. Dixo el diablo: "yo so dela companya de Lucifer e fue inbiado que lo engaynasse a este cavallero. Porque non podía enbargarlo de la oración de santa María, en esta figura me aplegué a él porque mas aýna lo podiesse engaynar. Mandado me era que si huna vez cessase de la oración de día e de noche, que lo matasse e lo lebasse al infierno". Esto dicto, partiosse el diablo. El caballero emendó todo el mal, esleyó logar por fazer penitencia en el desierto.

\section{[7: El hijo que fue encomendado al diablo, $f$. 76v]}

Era hun buen honbre e abía su muger e díxole el marido: "tengamos castidat". Dixo ella: "plázeme pues que amos buenos fijos". Tomaron castidat para XVII annos. Acaeció que hun día de pascoa vestiosse sus vestiduras e puso bien su tocadura e cubdiciolla su marido. Dixo ella: "esta creatura que nos agora faremos acomiendo al diablo".

Et parió hun fijo e púsolo a ler. Aprendió a tan bien que fue recebido con los buenos. Quando venía el fijo a la su madre a ler, la su madre comencaba plorar e pregu[n]tole a la madre por qué ploraba. Dixo ella de cómo le abía comendado al diablo. Dexó la riqueza e fue a buscar que le diesse consejo de la anima e falló hun hermitano que abía su vida con Dios e díxoli su [tachado: ver] fazienda. Dixo el hermitano: "yo te lo sabré como a de ser de ti". Enbió el hermitano [se interrumpe]. 


\section{$\infty 89$}

Los exempla del códice 48 de la Biblioteca de la Catedral de Pamplona

RESUMEN: Este artículo analiza una colección de exempla de la Biblioteca de la Catedral de Pamplona de la segunda mitad del siglo xv. Son versiones de relatos muy difundidos y conocidos, con la particularidad de estar escritos en romance navarro. Concebidos para ser empleados para ilustrar y hacer más asequibles los sermones, son una fuente valiosa y representativa de la espiritualidad bajomedieval y de las estrategias empleadas por la Iglesia para transmitir las verdades de fe y los comportamientos morales correctos.

Palabras Clave: Exemplum. Predicación. Sermones. Siglo xv. Literatura ejemplar. Retórica.

\section{The Exempla of the Codex 48 of the Library of the Cathedral of Pamplona}

ABSTRACT: This article analyzes an exempla collection of the Library of the Cathedral of Pamplona, from the second half of the $15^{\text {th }}$ century. They are versions of already known tales, with the singularity of being written in navarrese, a romance dialect. Conceived to be used for illustrating and making sermons more understandable, they constitute a valuable information source about late medieval spirituality, and also about the strategies used by preachers in order to transmit the truths faith of and inculcate ethical conduct.

Keywords: Exemplum. Preaching. Sermons. 15 $5^{\text {th }}$ Century. Exemplary literature. Rhetoric. 